\title{
Financiamento da educação e indicadores de qualidade: um estudo exploratório de seis municípios brasileiros
}

\author{
Financing education and quality indicators: \\ an exploratory study about six brazilian municipalities \\ Financiamiento de la educación y los indicadores de calidad: \\ un estudio exploratorio sobre seis municipios brasileños \\ ANDRÉA BARBOSA GOUVEIA \\ ANDREA POLENA
}

\begin{abstract}
Resumo: Este trabalho refere-se a resultado parcial da pesquisa Qualidade no ensino fundamental: uma leitura das condições de efetividade dos sistemas estaduais e municipais de ensino a partir de indicadores de financiamento, condições de oferta e resultados escolares, financiada pela CAPES/INEP/ Observatório da educação. O trabalho objetiva articular indicadores de desenvolvimento econômico e de desenvolvimento social e indicadores educacionais para problematizar as condições de qualidade de oferta educacional em seis municípios brasileiros localizados em três estados: Aracaju e Ilha das Flores, em Sergipe; Belo Horizonte e Cataguases, em Minas Gerais; Curitiba e Marmeleiro, no Paraná. Para analisar as condições de qualidade de ensino nas redes, utilizou-se o indicador Índice de Condições de Qualidade (ICQ) gerado a partir dos questionários de contexto da Prova Brasil. Os resultados evidenciam um cenário de crescimento dos recursos nos municípios, com reflexo no crescimento dos gastos por aluno ano; também evidenciam a manutenção de desigualdades de capacidade de investimento, que, contraditoriamente, não podem ser flagradas exclusivamente no movimento do ICQ.
\end{abstract}

Palavras-chave: Financiamento da educação, condições de qualidade, gasto aluno/ano.

\begin{abstract}
This work refers to partial results of the research "Quality in elementary education: a reading of the effectiveness conditions of state and local systems of education from financing indicators, supply conditions and school results", funded by CAPES/INEP/Observatory on Education. The work aims to articulate economic development indicators, social development and educational indicators to discuss the conditions of educational supply of quality in six municipalities located in three states: Aracaju and Ilha das Flores (Sergipe), Belo Horizonte and Cataguases (Minas Gerais), and Curitiba and Marmeleiro (Paraná). To analyze the quality of teaching conditions in the networks we used the Quality Conditions Index indicator (ICQ) generated from context questionnaires from Brazil Exam. The results show a resource growth scenario in the municipalities reflected in the growth of spending per pupil by year. It also highlights the maintenance of inequalities on the investment capacity, but paradoxically they can't be caught solely on the ICQ movement.
\end{abstract}


Keywords: Education funding, educations quality conditions, per pupil spending by year.

Resumen: Resultados parciales de la investigación "Calidad en la educación basica: una lectura de las condiciones de eficacia de los sistemas de educación desde los indicadores de financiación, la oferta y las condiciones de ejecución de la escuela provincial y municipal", financiado por la CAPES/INEP/ Observatorio de la Educación. El trabajo tiene como objetivo articular los indicadores del desarrollo económico, el desarrollo social y los indicadores de educación para discutir las condiciones de la oferta educativa de calidad en seis municipios situados en tres estados: Aracaju y la Ilha das Flores (Sergipe), Belo Horizonte y Cataguases (Minas Gerais) y Curitiba y Marmeleiro (Paraná). Para analizar la calidad de las condiciones de enseñanza en las redes utiliza el indicador de Índice de Condiciones de Calidad (ICQ) generado por cuestionarios de contesto de Prueba Brasil. Los resultados muestran un escenario de crecimiento de los recursos en los municipios, que se refleja en el crecimiento de los gastos anuales por los estudiantes, también destaca el mantenimiento de la capacidad de inversión de las desigualdades, pero paradójicamente no puede capturarse únicamente en movimiento ICQ.

Palabras clave: Financiación de la educación, las condiciones de calidad, la inversión por estudiante por año.

\section{O FINANCIAMENTO DA EDUCAÇÃO NO BRASIL E A IMPORTÂNCIA DE CONHECER AS FINANÇAS MUNICIPAIS}

No Brasil, o financiamento da educação pública sustenta-se no desenho de repartição de competências a partir do princípio de vinculação da receita de impostos dos diferentes entes federados à Manutenção e Desenvolvimento do Ensino (MDE). Isso tem garantido, historicamente, uma estabilidade relativa aos investimentos (FARENZENA, 2006) e significa que, em tempos de crescimento econômico, o investimento em educação cresce de forma quase inercial como reflexo do aumento da arrecadação, o oposto acontecendo em contextos de crise, quando há queda na arrecadação.

De toda forma, há grande consenso na área sobre o papel relevante que tem o mecanismo da vinculação em termos de proteção ao desenvolvimento da política educacional. Assim, a regra de que cabe aos municípios aplicar pelo menos $25 \%$ de sua receita de impostos, inclusive as provenientes de transferências em MDE, significa reconhecidamente a possibilidade de acompanhamento da receita dos municípios brasileiros e de análise das condições de investimento em educação.

As análises do potencial das receitas vinculadas, presentes no âmbito municipal, têm revelado o contexto de grandes desigualdades, que expressam, no campo da educação, as desigualdades de desenvolvimento econômico e social históricas no país. Assim, pode-se encontrar diferentes pesquisas que 
demonstram a variação significativa de recursos disponíveis, quando se considera a capacidade de investimento em educação (BREMAEKER, 2011). Essa variação na capacidade de financiamento encontra-se com um contexto de disformidade também no formato da divisão de responsabilidades pela oferta educacional no Brasil (ZAMPIRI, 2014). Ainda que a legislação indique a prioridade dos municípios com relação ao ensino fundamental e a educação infantil e que as políticas de fundos, em especial do FUNDEF, tenha representado uma indução forte à municipalização (PINTO, 2007), o formato dessa oferta no território nacional é ainda variado e se relaciona não só à história recente, mas à forma como as redes municipais foram desenvolvendo-se no país.

Dessa forma, compreender como o país garante condições de oferta educacional, considerando-se o padrão de investimento público, requer que se conheça e se reconheça a diversidade do âmbito local no país. Assim, este trabalho propõe-se contribuir com o debate, a partir de um recorte específico da realidade de seis cidades selecionadas, no âmbito da pesquisa Qualidade no ensino fundamental: uma leitura das condições de efetividade dos sistemas estaduais e municipais de ensino a partir de indicadores de financiamento, condições de oferta e resultados escolares'.

O estudo dos municípios de Aracaju e Ilha das Flores, em Sergipe; Belo Horizonte e Cataguases, em Minas Gerais; Curitiba e Marmeleiro, no Paraná compõe um conjunto de estudos de caso que pretendem observar a relação que pode haver entre condições de financiamento e condições de oferta, considerandose diferenças de porte municipal. A escolha dessas cidades tem relação com as premissas anteriores acerca da necessidade de se conhecer a educação brasileira a partir do reconhecimento da diversidade de composições de oferta e das desigualdades de condições para essa oferta, também tem relação com o objetivo da pesquisa, de compreender como as diferentes condições de financiamento têm-se convertido em diferentes condições de qualidade da oferta educacional.

O conceito de qualidade na educação é complexo e exige que se considere o produto do processo educacional, que, como lembra Paro (1998), é sempre o aluno educado. No âmbito da pesquisa aqui em debate, propõe-se discutir de maneira mais pontual a ideia de qualidade; por isso, utilizamos o conceito de condições de qualidade, ou seja, aqueles aspectos sem os quais se pode considerar que a efetivação de um projeto educacional terá dificuldades de garantir o pleno desenvolvimento humano. Assim, o conceito de condições de qualidade implica condições mínimas que gerem igualdade e incorpora a preocupação de que a escola se volte para o tempo presente dos estudantes. Por isso, esse conceito implica a garantia não apenas de uma promessa de futuro, mas de condições

1 Pesquisa realizada pelo Núcleo de Pesquisa em Políticas Educacionais da UFPR, financiada pela CAPES no âmbito do Programa Observatório da Educação. 
de realização de sua vida plena no tempo vivido no espaço escolar (WALZER, 2003). Essa preocupação permite problematizar a efetividade da ação do Estado na garantia de condições de qualidade que permitam aos estudantes usufruir o agora, antes de perguntar-se sobre a efetividade do projeto de futuro para esses sujeitos.

\section{O ÍNDICE DE CONDIÇÕES DE QUALIDADE COMO CRITÉRIO PARA DISCUSSÃO DAS CONDIÇÕES DE FINANCIAMENTO NOS MUNICÍPIOS}

Analisar a efetividade da política educacional no âmbito subnacional brasileiro requer que se estabeleça em que parâmetros se considera efetiva uma política, debate este amplo e com muitas nuances. De forma muito provisória, pode-se definir aqui que o acesso, medido pela expansão da matrícula, a cobertura educacional e os resultados em avaliações em larga escala podem ser indícios de algum grau de efetividade da política pública na garantia do direito à educação. No âmbito da pesquisa anteriormente citada, porém, a questão central são as condições de oferta que têm sido estabelecidas e sob que patamar de investimento público se constrói a escola brasileira, hoje em diferentes contextos municipais.

Para dimensionar as condições de oferta, a pesquisa desenvolveu um Índice de Condições de Qualidade (ICQ) a partir de informações dos questionários de contexto que compõem o Sistema Nacional de Avaliação da Educação Básica (SAEB), em especial no formato que este toma no âmbito da Prova Brasil. Assim, a partir de questões escolhidas sobre condições das escolas, condições de trabalho do professor e condições de gestão foi construído um indicador sintético (GOUVEIA; SCHNEIDER; SOUZA; 2011) para possibilitar uma leitura das condições de oferta nas redes públicas de ensino no Brasil. Para dimensionar as condições de investimento, a análise recai sobre os valores do gasto por aluno/ano, apurados a partir dos dados do Sistema Finanças do Brasil (FINBRA), cotejados com o Sistema de Informações sobre Orçamentos Públicos em Educação (SIOPE).

Cabe lembrar que as informações sobre despesas educacionais no caso brasileiro são bastante controversas. Apesar de a informação estar disponível, a qualidade dessa informação é bastante frágil; em geral, os dados disponíveis sobre despesas no Brasil são muito agregados e podem não revelar o que se faz efetivamente com os recursos. Assim, o maior desafio é, a partir da apuração do valor investido por aluno anualmente nas redes, responder sobre até que ponto essas despesas possibilitam condições de realização da política educacional adequada aos interesses públicos. 
Na direção de investigar em que medida os gastos em educação têm relação com condições de qualidade de oferta, a pesquisa anteriormente mencionada tem, como última fase, estudos de caso de redes públicas que apresentaram variação positiva significativa nas condições de oferta medida pelo ICQ. Foram realizados seis estudos em municípios que estivessem em diferentes estados da federação; entre esses casos incluíram-se obrigatoriamente as capitais dos estados e uma rede de ensino que possuísse entre 2.000 e 10.000 matrículas. Propõe-se aqui uma aproximação com os casos a partir da leitura dos indicadores de financiamento, com indicadores sociais e com o ICQ, com o objetivo de se problematizar em que medida o gasto aluno (GA) se relaciona com condições de qualidade de oferta educacional e com condições sociais de igualdade.

\section{AS CONDIÇÕES DE FINANCIAMENTO NOS MUNICÍPIOS SELECIONADOS}

A partir da seleção dos municípios anteriormente mencionados, buscouse comparar alguns indicadores sociais e econômicos, de forma a construir um contexto para a análise da oferta educacional e das condições de financiamento da educação, observando-se o que há de comum e de singular nos casos em análise. As consultas foram feitas nas páginas do Instituto Brasileiro de Geografia e Estatística (IBGE), Instituto Nacional de Estudos e Pesquisas Educacionais Anísio Teixeira (INEP) e Portal do Fundo Nacional de Desenvolvimento da Educação (FNDE) - SIOPE, sendo que os valores utilizados foram atualizados pelo Índice Nacional de Preço ao Consumidor (INPC) de dezembro de $2013^{2}$. Os anos de 2007, 2009 e 2011 foram escolhidos com base em dados colhidos na pesquisa inicial que desenvolveu o ICQ.

O primeiro indicador utilizado foi o Produto Interno Bruto (PIB), ferramenta que possibilita mensurar a capacidade de geração de riqueza de determinado espaço geográfico em determinado período. Por meio da análise desse indicador e de sua combinação com outros índices pode-se analisar o perfil de desenvolvimento econômico dos casos em discussão.

A Tabela 1 apresenta o PIB nacional e os respectivos PIBs municipais, a preços correntes, e sua variação nos anos de 2007, 2009 e 2011. Pode-se observar que em todos os casos houve aumento percentual, sendo que, entre 2007 e 2009, a variação nacional foi muito maior do que as encontradas nos municípios analisados, mas inferior, se comparada a 2009/2011. Isso pode ser explicado, em parte, pelos efeitos decorrentes da crise econômica internacional, que desacelerou a economia 
brasileira. Com a estabilização pós-crise, houve reaquecimento da economia em 2010, e certo recuo em 2011, o que gerou, na comparação 2009/2011, incremento do PIB nacional, assim como, em todos os municípios ${ }^{3}$. No segundo período os índices de variação se aproximam, mesmo quando comparados municípios e capitais.

Tabela 1 - Produto Interno Bruto a preços correntes (R\$1.000), casos selecionados - valores reais.

\begin{tabular}{|c|c|c|c|c|c|}
\hline & $\mathbf{2 0 0 7}$ & $\mathbf{2 0 0 9}$ & $\begin{array}{c}\text { Var } \\
\mathbf{0 7} \text { a 09 }\end{array}$ & $\mathbf{2 0 1 1}$ & $\begin{array}{c}\text { Var } \\
\text { 09 a 11 }\end{array}$ \\
\hline Brasil & $3.771 .744 .627,71$ & $4.111 .239 .051,90$ & $9,00 \%$ & $4.668 .220 .686,50$ & $13,55 \%$ \\
\hline Aracaju & $8.884 .590,20$ & $9.016 .250,97$ & $1,48 \%$ & $10.391 .990,24$ & $15,26 \%$ \\
\hline $\begin{array}{c}\text { Ilha das } \\
\text { Flores }\end{array}$ & $46.671,72$ & $48.485,30$ & $3,89 \%$ & $52.580,67$ & $8,45 \%$ \\
\hline $\begin{array}{c}\text { Belo } \\
\text { Horizonte }\end{array}$ & $54.258 .888,58$ & $56.767 .636,71$ & $4,62 \%$ & $61.968 .182,81$ & $9,16 \%$ \\
\hline Cataguases & $976.314,75$ & $988.213,10$ & $1,22 \%$ & $1.093 .546,41$ & $10,66 \%$ \\
\hline Curitiba & $54.031 .791,46$ & $58.052 .064,51$ & $7,44 \%$ & $65.445 .494,47$ & $12,74 \%$ \\
\hline Marmeleiro & $160.044,71$ & $170.121,12$ & $6,30 \%$ & $192.413,88$ & $13,10 \%$ \\
\hline
\end{tabular}

Fonte: IBGE ${ }^{4}$

Notas: os valores foram corrigidos pelo INPC de dezembro/2013

A medida da riqueza não é sinônima, infelizmente, de condições de qualidade de vida ou distribuição dessa riqueza no contexto municipal. Cabe comparar esse indicador, eminentemente econômico, com outros aspectos que permitam observar as condições sociais dos municípios. Dessa forma, pode-se utilizar o IDHM, que não se limita ao crescimento econômico, mas é composto por: Longevidade (esperança de vida ao nascer); Educação (média de anos de estudo da população com 25 anos ou mais e expectativa de anos de estudo) e Renda (Renda Nacional Bruta per capita), indicador esse que varia de zero a um: quanto mais próximo de um, mais desenvolvido é o município. A Tabela 2 apresenta esses valores, podendo-se observar que Ilha das Flores e Marmeleiro, municípios com o menor PIB segundo a Tabela 1, apresentavam os menores IDHM, quando comparados com o do Brasil, em 2000. Em 2010, apenas Ilha das Flores permanece em condição de "Baixo desenvolvimento humano". Ainda que Marmeleiro possua o segundo menor IDHM, apresentou importante incremento

3 IBGE: Comentário - A Economia Brasileira no $2^{\circ}$ Trimestre de 2013: Visão Geral. Disponível em: ftp://ftp.ibge.gov.br/Contas_Nacionais/Contas_Nacionais_Trimestrais/Comentarios/pib-volval_201302comentarios.pdf. Acessado em: 02/04/2014

4 IBGE: Tabela PIB. Disponível em: ftp://ftp.ibge.gov.br/Pib_Municipios/2010/base/ base_2005_2010_xls.zip 
na década. Os demais municípios também têm avanços significativos nesse indicador.

Tabela 2 - IDHM Brasil e municípios, casos selecionados.

\begin{tabular}{|c|c|c|c|}
\hline & IDHM 2000 & IDHM 2010 & $\begin{array}{c}\text { Condição de } \\
\text { Desenvolvimento } \\
\text { Humano em 2010 }\end{array}$ \\
\hline Brasil & 0,612 & 0,727 & Alto \\
\hline Aracaju & 0,648 & 0,770 & Alto \\
\hline IIha das Flores & 0,421 & 0,562 & Baixo \\
\hline Belo Horizonte & 0,726 & 0,810 & Muito Alto \\
\hline Cataguases & 0,659 & 0,751 & Alto \\
\hline Curitiba & 0,750 & 0,823 & Muito Alto \\
\hline Marmeleiro & 0,594 & 0,722 & Alto \\
\hline
\end{tabular}

Fonte: IBGE - Atlas do desenvolvimento humano 2013.

Ainda que o ponto de partida dos casos seja diferente, a comparação de movimentação do IDHM é interessante, pois ao longo da década o incremento das condições sociais relaciona-se positivamente com o crescimento da economia.

No caso de Ilha das Flores, por exemplo, o IDHM ainda é considerado "Baixo" (0,562), mas analisando-se a vulnerabilidade social, há uma considerável diminuição na mortalidade infantil, que passa de 55,91 (2000) para 30,40 (2010) a cada mil nascidos vivos; redução de crianças de quatro e cinco anos fora da escola, de 16,65\% (2000) para 10,33\% (2010) e de pessoas em domicílios com abastecimento de água e esgotamento sanitário inadequados, de 30,48\% (2000) para 16,83\% (2010), dentre outros indicadores que apresentaram melhoras, elevando, dessa forma, a variação percentual entre 2000/2010.

Comparativamente aos demais casos, parecem possíveis outras formas de ler os indicadores compostos no IDHM. Se fixarmos, por exemplo, o tema da mortalidade infantil e do número de crianças de quatro e cinco anos na educação infantil, pode-se confirmar que Ilha das Flores apresenta as piores condições, já apresentadas no parágrafo anterior, seguida de Marmeleiro com 12 mortes para cada mil nascidos vivos (2010) e um percentual de 16,94\% de crianças fora da escola. Aracaju está na terceira posição no indicador agrupado, porém apresenta 15,61 mortes para cada mil nascidos vivos (2010), mas tem 10,70\% de crianças de quatro a cinco anos fora da escola. No caso de Cataguases o IDHM é considerado alto $(0,751)$, verificamos a mortalidade infantil de 12,90 (2010) para cada mil nascidos vivos e um alto atendimento na pré escola, com apenas 2,82\% de crianças de quatro e cinco anos fora da escola.

Nos dois casos considerados na faixa "Muito alto", Belo Horizonte 
apresenta a mortalidade infantil de 12,95 (2010) para cada 1000 nascidos vivos e $14,83 \%$ crianças de quatro a cinco anos fora da escola em Curitiba a mortalidade infantil é 11,91 (2010) para cada mil nascidos vivos e apresenta percentual de $16,38 \%$ crianças de quatro a cinco anos fora da escola. Observar esses elementos desagregados permite perceber que olhar as singularidades dos casos pode ajudar a compreender melhor os impasses e desafios que os municípios brasileiros têm para garantir o direito à educação, ainda que em um contexto de melhora dos indicadores sociais mais amplos.

Para o que nos interessa diretamente neste trabalho, a política educacional, é preciso considerar as condições de financiamento da educação nesses contextos. Assim, a Tabela 3 apresenta a Receita de impostos ${ }^{5}$ e transferências vinculadas, nos municípios.

Tabela 3 - Receita de impostos e transferências vinculadas, casos selecionados- valores reais.

\begin{tabular}{|c|c|c|c|c|c|}
\hline & $\mathbf{2 0 0 7}$ & $\mathbf{2 0 0 9}$ & $\begin{array}{c}\text { Var } \\
\mathbf{0 7} \mathbf{~ e 9}\end{array}$ & $\mathbf{2 0 1 1}$ & $\begin{array}{c}\text { Var } \\
\mathbf{0 9} \mathbf{~ e ~ 1 1}\end{array}$ \\
\hline Aracaju & $484.508 .591,46$ & $523.425 .102,37$ & $8,03 \%$ & $741.035 .327,87$ & $41,57 \%$ \\
\hline Ilha das Flores & $6.968 .594,83$ & $7.372 .831,31$ & $5,80 \%$ & $8.671 .679,93$ & $17,62 \%$ \\
\hline $\begin{array}{c}\text { Belo } \\
\text { Horizonte }\end{array}$ & $2.885 .813 .720,82$ & $3.207 .487 .701,22$ & $11,15 \%$ & $3.912 .090 .731,12$ & $21,97 \%$ \\
\hline Cataguases & $49.929 .721,71$ & $52.646 .835,00$ & $5,44 \%$ & $60.823 .302,47$ & $15,53 \%$ \\
\hline Curitiba & $2.185 .882 .032,42$ & $2.475 .617 .411,57$ & $13,25 \%$ & $2.764 .970 .105,89$ & $11,69 \%$ \\
\hline Marmeleiro & $14.920 .530,19$ & $17.052 .856,75$ & $14,29 \%$ & $22.712 .438,60$ & $33,19 \%$ \\
\hline
\end{tabular}

Fonte: FNDE - SIOPE - Demonstrativos municipais - Anexo X

Notas: os valores foram corrigidos pelo INPC de dezembro/2013

Confrontando as Tabelas 1 e 3 pode-se verificar que Curitiba e Marmeleiro apresentam a maior variação do PIB no período de 2007/2009 e isto se reflete no maior percentual de ampliação da receita vinculada. No período 2009/2011, a maior expansão do PIB se deu em Aracaju e Marmeleiro, o que novamente se reflete na expansão da receita de impostos. Assim, o crescimento econômico parece garantir, nesses casos, pelo mecanismo da vinculação da receita, cenário melhor para o investimento em educação.

O Gráfico 1 sintetiza a variação do PIB e da receita de impostos e da transferência vinculada em todo o período. Observa-se que a receita de

$5 \quad$ Fazem parte dessa receita as de: impostos municipais (ISS, IPTU, ITBI e IRRF), impostos estaduais (ICMS, ITCD, IPVA e IRRF), transferências da União (FPM, ITR, IOF - Ouro e Lei Kandir - Município, FPE, IPI - Exp., IOF - Ouro e Lei Kandir -Estado), Transferências do Estado (ICMS, IPVA, IPI- Exportação), Outras Receitas Correntes, Receitas da dívida ativa tributária de impostos, multas e juros de mora e correção monetária. 
impostos tem incremento maior que o PIB, o que pode decorrer do conjunto de transferências constitucionais a que o município tem direito, especialmente o Fundo de Participação dos Municípios (FPM), que depende menos do desenvolvimento local. Evidencia-se, ainda, que o maior crescimento do PIB está nas capitais, exceto em relação ao município de Marmeleiro, assim como o maior incremento da receita.

\section{Gráfico 1 - Variações percentuais de PIB e Receita de Impostos e transferências vinculadas $-2007 / 2011$, casos selecionados.}

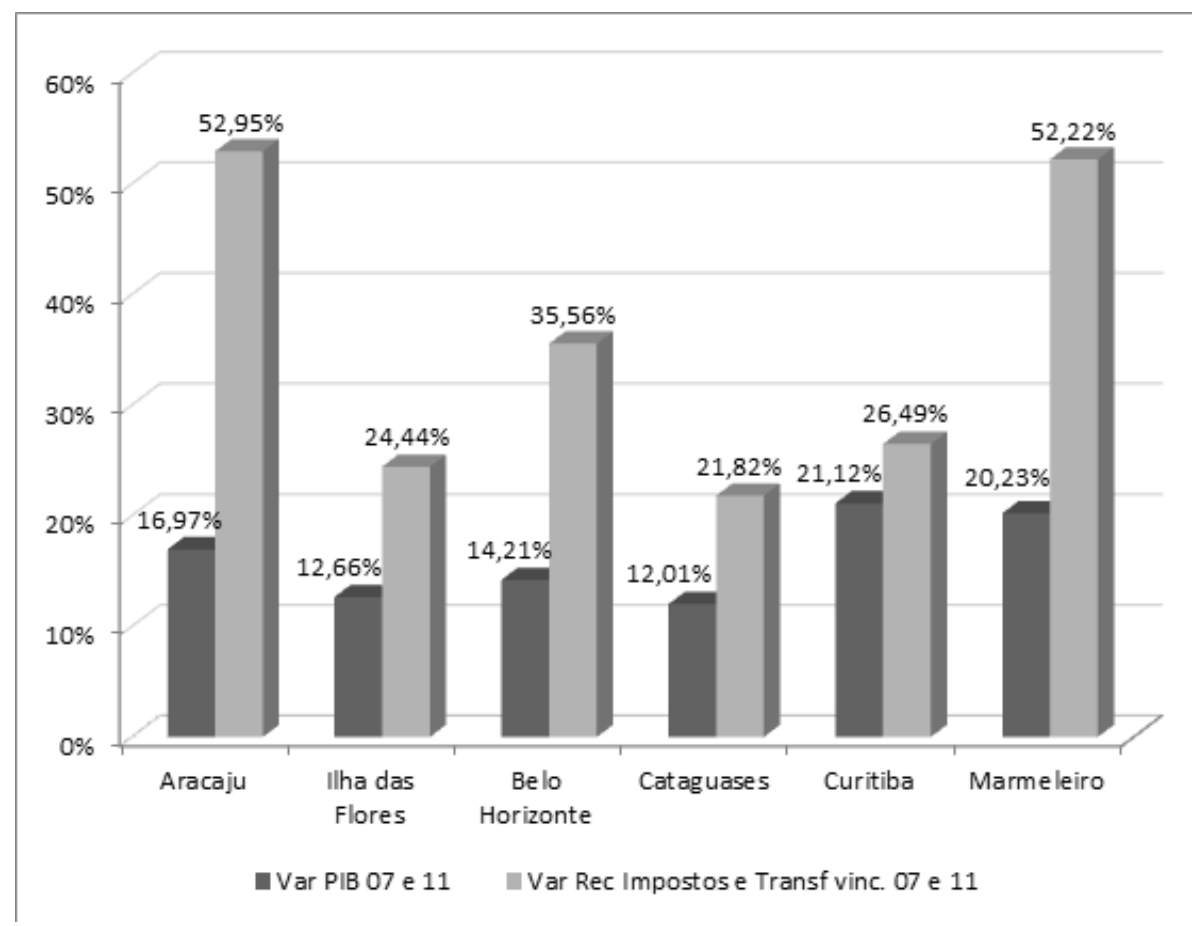

Fonte: Atlas do desenvolvimento humano 2013 (IBGE). Elaborado pelas autoras.

Esse cenário de condições de financiamento da política pública precisa encontrar a dinâmica de demanda por serviços públicos. Neste trabalho temos o intento de observar a dinâmica populacional dos municípios e a correspondente dinâmica da demanda por educação, indicada aqui pelo movimento da matrícula.

A Tabela 4 apresenta o número de matrículas e estimativa da população nos municípios nos anos de 2007 e 2011 . Verifica-se que, em todos os municípios analisados, há um decréscimo de matrículas, apesar de haver aumento percentual na população estimada nos municípios de Aracaju, Cataguases e Marmeleiro. Isso 
pode sugerir que não tenha havido, efetivamente, esse acréscimo populacional, ou que ele tenha ocorrido em idade não escolar ou, ainda, por razões de ajuste de fluxo nas redes de ensino.

Tabela 4 - Matrículas na Educação Básica da Rede Municipal e População (estimativa), casos selecionados.

\begin{tabular}{|c|c|c|c|c|c|c|}
\hline Municípios & \multicolumn{3}{|c|}{$\begin{array}{c}\text { Matriculas Educação Básica } \\
\text { na Rede Municipal }\end{array}$} & \multicolumn{3}{c|}{ População - Estimativa } \\
\hline & $\mathbf{2 0 0 7}$ & $\mathbf{2 0 1 1}$ & Variação & $\mathbf{2 0 0 7}$ & $\mathbf{2 0 1 1}$ & Variação \\
\hline Aracaju & 34.052 & 28.862 & $-15,24 \%$ & 520.207 & 579.563 & $11,41 \%$ \\
\hline $\begin{array}{c}\text { Ilha das } \\
\text { Flores }\end{array}$ & 1.929 & 1.663 & $-13,79 \%$ & 8.598 & 8.354 & $-2,84 \%$ \\
\hline $\begin{array}{c}\text { Belo } \\
\text { Horizonte }\end{array}$ & 180.760 & 170.581 & $-5,63 \%$ & 2.412 .937 & 2.385 .640 & $-1,13 \%$ \\
\hline Cataguases & 6.846 & 5.612 & $-18,03 \%$ & 67.447 & 70.201 & $4,08 \%$ \\
\hline Curitiba & 131.505 & 131.335 & $-0,13 \%$ & 1.797 .408 & 1.764 .541 & $-1,83 \%$ \\
\hline Marmeleiro & 1.387 & 1.239 & $-10,67 \%$ & 13.156 & 13.919 & $5,80 \%$ \\
\hline
\end{tabular}

Fonte: IBGE e INEP ${ }^{6}$

Interessante observar que, quando comparamos o percentual de matrículas em relação à população (Tabela 5), há uma queda na participação da matrícula no total da população, com a única exceção de Curitiba, que apresentou leve aumento.

Tabela 5 - Variação percentual nas matrículas em relação à população, casos selecionados.

\begin{tabular}{|c|c|c|}
\hline Municípios & $\mathbf{2 0 0 7}$ & $\mathbf{2 0 1 1}$ \\
\hline Aracaju & $6,55 \%$ & $4,98 \%$ \\
\hline Ilha das Flores & $22,44 \%$ & $19,91 \%$ \\
\hline Belo Horizonte & $7,49 \%$ & $7,15 \%$ \\
\hline Cataguases & $10,15 \%$ & $7,99 \%$ \\
\hline Curitiba & $7,32 \%$ & $7,44 \%$ \\
\hline Marmeleiro & $10,54 \%$ & $8,90 \%$ \\
\hline
\end{tabular}

Fonte: IBGE e INEP - Dados tabulados pelas autoras

Observe-se que Ilha das Flores é o município em que os indicadores sociais são mais vulneráveis e que tem o maior percentual de população em idade escolar sob responsabilidade da rede municipal de ensino. A participação da rede municipal cai para um atendimento perto de $8 \%$ em Cataguases e nas 
capitais estudadas não chega a 8\%. Este é um forte elemento de desigualdade de condições de oferta, visto que em condições de menor produção de riqueza, há maior dependência da população em relação ao poder municipal.

Frente a essas condições sociais, de disponibilidade orçamentária e de atendimento escolar mensurado na matrícula, pode-se avançar para o investimento realizado em educação como forma de investigar a hipótese de que a ampliação das condições de oferta reveladas pelo ICQ possa ser decorrente de ampliação nas condições de investimento em educação.

A Tabela 6 apresenta as despesas em Manutenção e Desenvolvimento do Ensino - $\mathrm{MDE}^{7}$. Pode-se observar que houve acréscimo na maioria dos casos em todos os períodos. Como era de se esperar, considerando o movimento da economia anteriormente destacado, as despesas têm variações menores entre 2007-2009, sendo negativa a variação em Marmeleiro, enquanto, no período de 2009-2011 em todos os casos se apresenta expansão considerável da despesa, inclusive em Marmeleiro.

Tabela 6 - Despesas em Educação (MDE), casos selecionados - valores reais.

\begin{tabular}{|c|c|c|c|c|c|}
\hline & 2007 & 2009 & $\begin{array}{c}\text { Var } \\
07 \text { e } 09\end{array}$ & 2011 & $\begin{array}{c}\text { Var } \\
09 \text { e } 11\end{array}$ \\
\hline Aracaju & $134.964 .354,02$ & $138.483 .501,31$ & $2,61 \%$ & $195.407 .560,14$ & $41,11 \%$ \\
\hline $\begin{array}{l}\text { Ilha das } \\
\text { Flores }\end{array}$ & $3.608 .273,26$ & $3.880 .156,61$ & $7,53 \%$ & $4.647 .733,58$ & $19,78 \%$ \\
\hline $\begin{array}{c}\text { Belo } \\
\text { Horizonte }\end{array}$ & $966.364 .336,03$ & $1.060 .882 .455,48$ & $9,78 \%$ & $1.296 .529 .993,07$ & $22,21 \%$ \\
\hline Cataguases & $16.750 .351,19$ & $18.184 .949,62$ & $8,56 \%$ & $21.534 .321,65$ & $18,42 \%$ \\
\hline Curitiba & $685.989 .942,39$ & $741.349 .863,10$ & $8,07 \%$ & $875.108 .477,47$ & $18,04 \%$ \\
\hline Marmeleiro & $4.475 .842,75$ & $4.276 .920,32$ & $-4,44 \%$ & $5.462 .414,49$ & $27,72 \%$ \\
\hline
\end{tabular}

Fonte: FNDE - SIOPE - Demonstrativos municipais - Anexo X

Notas: os valores foram corrigidos pelo INPC de dezembro/2013

Cabe observar se as despesas se movimentaram no mesmo ritmo das receitas de impostos e transferências vinculadas e das Despesas em Educação - MDE. Observando o Gráfico 2, pode-se perceber que Curitiba, Cataguases

\footnotetext{
7 São ações financiáveis com os recursos do MDE: I - remuneração e aperfeiçoamento do pessoal docente e demais profissionais da educação; II - aquisição, manutenção, construção e conservação de instalações e equipamentos necessários ao ensino; III - uso e manutenção de bens e serviços vinculados ao ensino; IV - levantamentos estatísticos, estudos e pesquisas visando precipuamente ao aprimoramento da qualidade e à expansão do ensino; $\mathrm{V}$ - realização de atividades-meio necessárias ao funcionamento dos sistemas de ensino; VI - concessão de bolsas de estudo a alunos de escolas públicas e privadas; VII - amortização e custeio de operações de crédito destinadas a atender ao disposto nos incisos deste artigo; VIII - aquisição de material didático-escolar e manutenção de programas de transporte escolar.
} 
e Ilha das Flores têm incremento das despesas maior que o da receita e pode sugerir um esforço municipal em relação à educação que não seja apenas reflexo do aumento da arrecadação, enquanto Marmeleiro, Belo Horizonte e Aracaju têm o movimento oposto. No caso específico de Marmeleiro o crescimento da receita é substancialmente maior que o crescimento das despesas em MDE.

\section{Gráfico 2 - Variações percentuais das despesas em MDE e Receita de impostos entre 2007 e 2011, casos selecionados - valores reais.}

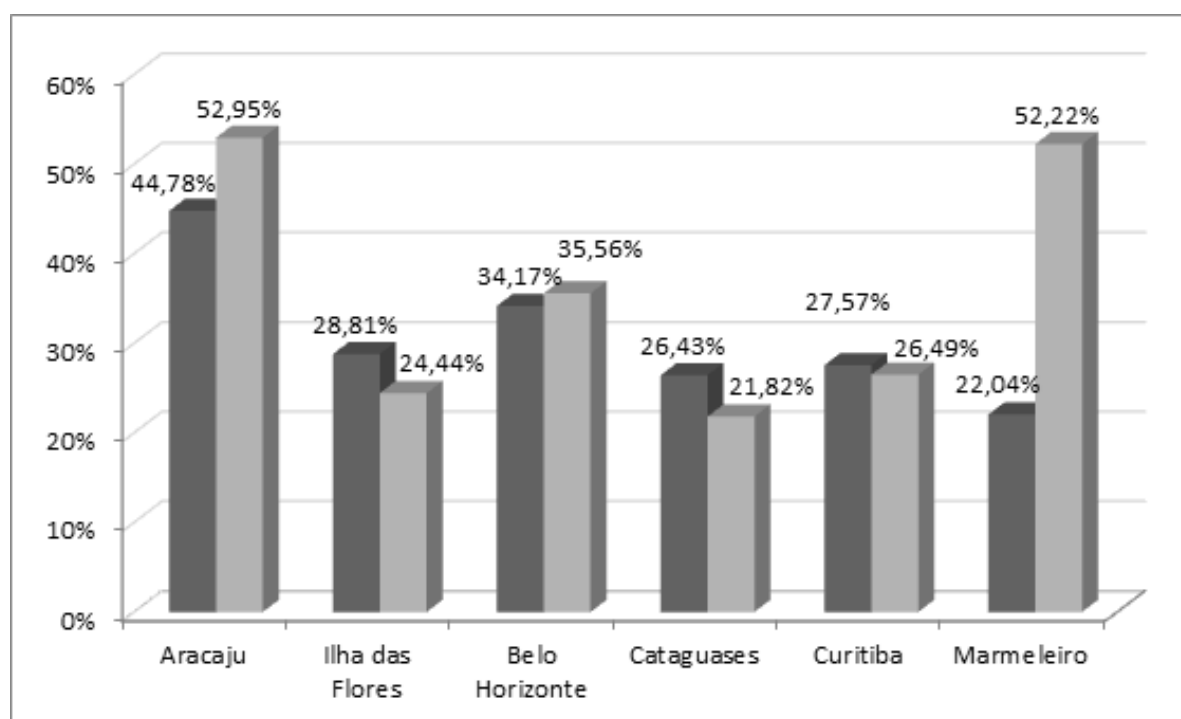

- Var despesas MDE 07 e $11 \quad$ Var receita imp e transf vinc 07 e 11

Fonte: FNDE - SIOPE - Dados tabulados pelas autoras.

Comparar o crescimento da despesa nos dá um panorama geral da direção do esforço dos municípios em relação ao investimento em educação; para dimensionar, porém, se esse crescimento garante as mesmas condições de oferta, é preciso especificar melhor a comparação. Uma forma é usar como indicador o gasto por aluno, para se dimensionar se esses municípios têm a mesma capacidade de oferta.

Considerando os valores do gasto aluno ano da Tabela 7, isto é, a divisão entre os valores das Despesas em MDE declarada ${ }^{8}$ pelos municípios e o número de matrículas na Educação Básica na rede Municipal, verificamos que há um incremento nos valores investidos em todos os casos. 
Tabela 7 - Gasto aluno (GA), casos selecionados - valores reais.

\begin{tabular}{|c|c|c|c|c|}
\hline & $\mathbf{2 0 0 7}$ & $\mathbf{2 0 0 9}$ & $\mathbf{2 0 1 1}$ & $\begin{array}{c}\text { \% de } \\
\text { crescimento } \\
\mathbf{0 7} \text { a 11 }\end{array}$ \\
\hline Aracaju & $3.963,48$ & $4.715,94$ & $6.770,41$ & $70,82 \%$ \\
\hline Ilha das Flores & $1.870,54$ & $2.183,54$ & $2.794,79$ & $49,41 \%$ \\
\hline Belo Horizonte & $5.346,12$ & $6.085,24$ & $7.600,67$ & $42,17 \%$ \\
\hline Cataguases & $2.487,87$ & $3.042,74$ & $3.837,19$ & $54,24 \%$ \\
\hline Curitiba & $5.216,46$ & $5.519,16$ & $6.663,18$ & $27,73 \%$ \\
\hline Marmeleiro & $3.227,00$ & $3.009,80$ & $4.408,73$ & $36,62 \%$ \\
\hline
\end{tabular}

Fonte: FNDE / SIOPE e Portal do INEP - Dados tabulados pelas autoras.

Notas: os valores foram corrigidos pelo INPC de dezembro/2013

Observe-se que Aracaju, Belo Horizonte e Marmeleiro, com aumento menor na despesa que na receita (Gráfico 2), apresentam crescimento significativo na despesa por aluno, em especial no primeiro caso, o que pode ser explicado por uma queda na matrícula de 15,24\% (Tabela 4) entre 2007 e 2011. Por outro lado, Curitiba e Cataguases tiveram aumento no gasto por aluno num cenário de ampliação geral das despesas em educação, como indicado anteriormente. $\mathrm{O}$ caso de Ilha das Flores chama atenção, pois tem incremento no gasto por aluno (49,41\%), tem diminuição da matrícula em 13,79\% (Tabela 4) no período de 2007 a 2011 e, ainda assim, é o menor investimento em todas as medidas.

Assim, pode-se considerar que a Tabela 7 evidencia uma diferença explícita nas condições de oferta nas redes de capitais (Belo Horizonte, Curitiba e Aracaju) que puderam gastar em média sete mil reais por aluno em 2011, enquanto os municípios menores, mesmo com incremento, chegaram a uma média próxima de 3,6 mil reais em 2011, mesmo com todos os mecanismos de redistribuição de recursos internos nos estados feitos, por exemplo, pelo Fundo de Manutenção e Desenvolvimento da Educação Básica e de Valorização dos Profissionais da Educação (FUNDEB).

Se levarmos em consideração os valores do FUNDEB, por aluno, estimado para cada Estado, nas séries iniciais do Ensino Fundamental urbano, Tabela 8, podemos verficar que Ilha das Flores aproxima-se do valor mínimo do estado, enquanto as capitais apresentam grande distância desses valores. Isto reforça a premissa de que há desigualdades e maior esforço no investimento em educação nos municípios de maior vulnerabilidade. 
Tabela 8 - Valor por aluno estimado por Estado - séries Iniciais EF urbano, casos selecionados.

\begin{tabular}{|c|c|c|c|}
\hline & $\mathbf{2 0 0 7}$ & $\mathbf{2 0 0 9}$ & $\mathbf{2 0 1 1}$ \\
\hline Aracaju & $1.781,09$ & $2.059,58$ & $2.215,83$ \\
\hline Ilha das Flores & $1.781,09$ & $2.059,58$ & $2.215,83$ \\
\hline Belo Horizonte & $1.723,27$ & $2.065,31$ & $2.144,31$ \\
\hline Cataguases & $1.723,27$ & $2.065,31$ & $2.144,31$ \\
\hline Curitiba & $1.803,90$ & $1.993,91$ & $2.006,74$ \\
\hline Marmeleiro & $1.803,90$ & $1.993,91$ & $2.006,74$ \\
\hline
\end{tabular}

Fonte: FNDE (2007, 2009, 2011).

Nota: valores corrigidos pelo INPC de dezembro/2013.

Ainda se pode considerar que os municípios que, na média, distanciam-se dos valores referência 1 no âmbito do FUNDEB, ou seja, os valores estimados como mínimos para o Ensino Fundamental urbano, têm maiores condições de, ao executarem as despesas, garantir incremento para o investimento nas etapas e modalidades de educação que têm comprovadamente mais custo, como, por exemplo, educação infantil e educação especial. Enquanto isso, Ilha das Flores, nosso caso mais vulnerável, terá maior dificuldade em diversificar os investimentos.

Retomando alguns dos dados anteriores, essa situação pode ser melhor discutida. A medida de vulnerabilidade evidencia situação bastante cruel em Ilha das Flores, que ainda apresentava, em 2010, o dobro de mortalidade infantil relativamente às demais; quando o indicador é especificamente educacional, porém, como, por exemplo, o percentual de crianças de quadro e cinco anos fora da préescola,os dados não têm relação tão imediata com as condições de financiamento, pois, nesse caso, as três capitais (Belo Horizonte 14\% de crianças fora, Curitiba, $16 \%$ de crianças fora e Aracaju, 20\% de crianças fora) apresentam indicadores bastante piores que os de Cataguases ( $2 \%$ de crianças fora), Marmeleiro (16\% de crianças fora) e, inclusive, Ilha das Flores (10\% de crianças fora). A concentração da população pode explicar, em parte, esse problema de atendimento da educação infantil, nas não de forma suficiente, visto que já evidenciamos que, em Ilha das Flores, a participação do poder público municipal na oferta de educação é muito mais significativa que nos demais municípios.

Esse cenário nos leva ao foco central da preocupação da pesquisa Qualidade no ensino fundamental: uma leitura das condiçoes de efetividade dos sistemas estaduais e municipais de ensino a partir de indicadores de financiamento, condiçoes de oferta e resultados escolares: como os investimentos em educação no âmbito das redes se convertem, ou não, em condições de qualidade de oferta. 
A partir dos questionários de contexto da Prova Brasil, foram selecionadas variáveis que indicassem condições de qualidade que pudessem ser impactadas diretamente pela política municipal, com incremento de recursos ou não. Assim o ICQ incorpora uma dimensão de condições de trabalho docente (escolaridade, salário por hora, tipo de vínculo com a rede de ensino); condições de infraestrutura da escola e condições de gestão na rede (salário do diretor, conselho de escola, projeto político pedagógico). Na composição final do ICQ, as condições de trabalho docente têm peso maior que as condições materiais das escolas e estas, peso maior que as condições de gestão (GOUVEIA; SCHNEIDER; SOUZA, 2011). A Tabela 9 sintetiza os dados do ICQ e do gasto aluno (GA) ano nos casos selecionados.

Tabela 9 - ICQ e GA nos anos de 2007 e 2011, casos selecionados por ordem de ICQ 2007.

\begin{tabular}{|c|c|c|c|c|}
\hline & ICQ 2007 & GA 2007 & ICQ 2011 & GA 2011 \\
\hline Ilha das Flores & 0,4496 & $1.870,54$ & 0,7555 & $2.794,79$ \\
\hline Cataguases & 0,4528 & $2.487,87$ & 0,5786 & $3.837,19$ \\
\hline Aracaju & 0,6240 & $3.963,48$ & 0,5876 & $6.770,41$ \\
\hline Curitiba & 0,7100 & $5.216,46$ & 0,7872 & $6.663,18$ \\
\hline Marmeleiro & 0,7290 & $3.227,00$ & 0,7415 & $4.408,73$ \\
\hline Belo Horizonte & 0,8095 & $5.346,12$ & 0,7831 & $7.600,67$ \\
\hline
\end{tabular}

Fonte: Prova Brasil - questionário de contexto (2007 e 2011). SIOPE (2007 e 2011) - Dados tabulados pelas autoras.

Observe-se que o ICQ 2007 cresce de maneira evidente na direção do GA; a leitura dos dados de 2011, porém, não é tão evidente assim. A condição do ICQ de Ilha das Flores é, pelos dados, bastante próxima da de Belo Horizonte e de Curitiba. O alto incremento do ICQ de Ilha das Flores, no período, foi o fator determinante para que a cidade compusesse os estudos de caso. Cataguases, também escolhida pelo incremento no ICQ, tem movimento mais esperado, ou seja, cresce na mesma direção do GA. Marmeleiro novamente apresenta o crescimento do ICQ coerente com o cenário de crescimento do gasto aluno/ano e, por isso, também compôs os estudos de caso.

Uma possível explicação para esse cenário está na distribuição dos pesos do ICQ, pois como as condições de trabalho do professor são o fator mais importante e, nesse caso, Ilha das Flores têm professores com ensino superior e estatutários, isso lhe confere uma situação melhor no indicador. Outro elemento pode ser o porte, pois um município pequeno, com poucas escolas, tem mais condições de manter a infraestrutura das escolas e, no retrato gerado pelo ICQ, 
ser identificado como portador de boas condições de oferta. O sentido oposto pode ser pensado no caso das capitais, que para garantir efetividade na política, precisam movimentar uma estrutura educacional bastante complexa. Todos esses elementos justificaram a ida a campo e a análise dos dados desse grupo de municípios. De toda forma, o cotejamento do ICQ com os gastos também permite problematizar que, em contextos de muitas dificuldades, como é o caso de Ilha das Flores, o aporte novo de recursos faz efeito nas condições de oferta educacional muito mais rapidamente do que em contextos em que já existe um investimento interessante e o desafio do incremento da qualidade precisa enfrentar aspectos mais amplos, como, por exemplo, gestão dos sistemas.

\section{CONSIDERAÇÕES FINAIS}

A proposta deste artigo é exploratória, ou seja, não se pretende aqui concluir de forma definitiva que relação há entre a ampliação de investimentos e as condições de qualidade, mas levantar indícios que possibilitem a leitura de casos específicos, selecionados a partir de instrumentos quantitativos, que mapearam as condições de riqueza, oferta de educação e qualidade de redes municipais brasileiras.

Nessa direção, pode-se considerar que os casos em análise evidenciam os efeitos que o movimento geral da economia, mensurados aqui pelo PIB, tem no âmbito do financiamento da educação, mas, ao mesmo tempo, evidenciam uma dinâmica própria que se relaciona, por exemplo, com a demanda por educação. Neste estudo, essa segunda percepção se deve aos indicadores de crescimento da receita, que nem sempre aparecem de forma imediatamente refletida no crescimento das despesas em educação.

A escolha de estudos de três capitais e três municípios de pequeno porte evidencia também as diferenças de condições de financiamento da educação, que são amplamente conhecidas na literatura educacional. Encontram-se, porém, alguns elementos aparentemente contraditórios que exigem maior aprofundamento, como o que tem sido a política educacional no âmbito subnacional, pois, se em termos de disponibilidade de investimento e esforço municipal, ficou evidente a demanda que Ilha das Flores, Marmeleiro e Cataguases têm para atender, em aspectos pontuais, por exemplo, a educação infantil de quatro e cinco anos, essas cidades se movimentam de maneira mais rápida que as capitais. Por outro lado, o elemento tamanho das redes parece dificultar a manutenção de condições equitativas de qualidade, o que poderia explicar os movimentos contraditórios no ICQ encontrados em 2011.

Finalmente, a leitura aqui proposta parece permitir afirmar que os retratos 
mensurados por indicadores gerais sobre política pública brasileira mapeiam bem perfis da realidade; os estudos de caso, porém, podem permitir aprofundar as nuances e compreender melhor os limites das políticas em curso. Agregue-se a isso a indicação de que compreender o que acontece nos grandes municípios é diferente de entender os desafios dos pequenos municípios; nesse sentido, pensar um pacto federativo que tenha como perspectiva a promoção de equidade de oferta e justiça social no âmbito educacional implica considerar escala como uma variável importante do debate político.

\section{REFERENNCIAS}

BRASIL. Banco Central do Brasil. Calculadora do cidadão. Disponível em: https://www3.bcb.gov.br/CALCIDADAO/publico/corrigirPorIndice. do?method=corrigirPorIndice. Acessado em: 31/03/2014.

IBGE. Atlas do Desenvolvimento Humano

$\begin{array}{llllr}\text { no } & \text { Brasil 2013. } & & \text { Disponível } & \text { em:http://atlasbrasil.org. } \\ \text { br/2013/pt/o_atlas/idhm/. } & \text { Acessado } & \text { em: } & \text { 03/04/2014. }\end{array}$

IBGE. Comentário - A Economia Brasileira no $2^{\circ}$ Trimestre de 2013: Visão Geral. Disponível em: ftp://ftp.ibge.gov. br/Contas_Nacionais/Contas_Nacionais_Trimestrais/Comentarios / pib-vol-val_201302comentarios.pdf. Acessado em: 02/04/2014.

IBGE Cidades. Disponível em: http://cidades. ibge.gov.br/xtras/home.php?lang=. Acesso em: 23/02/2014.

FNDE. Portaria Interministerial $\mathbf{n}^{\mathbf{0}} \mathbf{1 0 3 0}$, de 6 de novembro de 2007. Define e divulga os parâmetros anuais de operacionalização do FUNDEB para o exercício de 2007; atualiza e divulga o valor da complementação da União ao FUNDEB em 2007.Disponível em: http:// www.fnde.gov.br/fnde/legislacao/portarias. Acessado em: 03/04/2014.

. FNDE. Portaria Interministerial $\mathbf{n}^{\mathbf{0}} \mathbf{1 7 2 1}$, de 7 de novembro de 2011 - Retificação da Portaria Interministerial MEC/MF no 477, de 28 de abril de 2011 e operacionalização do FUNDEB no exercício de 2011. Disponível em: http://www.fnde.gov.br/fnde/legislacao/portarias. Acessado em: 03/04/2014.

FNDE. Portaria MEC $\mathrm{n}^{\mathbf{0}}$ 788, de 14 de agosto de 2009 - Redefine e divulga os parâmetros anuais de operacionalização 
do FUNDEB para o exercício de 2009. Disponível em: http://www. fnde.gov.br/fnde/legislacao/portarias. Acessado em: 03/04/2014. . FNDE. SIOPE. Relatório resumido da execução orçamentária - RREO - Anexo X da Lei de Responsabilidade Fiscal (A partir de 2006). Disponível em: http://www.fnde.gov.br/fnde-sistemas/sistema-siopeapresentacao/siope-relatorios-municipais. Acessado em: 25/02/2014.

$\begin{array}{lcccr}\text {. Portal do INEP. } & \text { Censo } & \text { Escolar. } & \text { Consulta a } \\ \text { matrícula. } & \text { Disponível } & \text { em: } & \text { http://portal.inep.gov.br/ } \\ \text { basica-censo-escolar-matricula\#. } & \text { Acessado } & \text { em: } & \text { 25/02/2014. }\end{array}$

BREMAEKER, François Eugene Jean de. A política de fundos para a educação e o impacto nas finanças dos estados e dos municípios. In: GOUVEIA, Andréa Barbosa; PINTO, José Marcelino Rezende; CORBUCCI, Paulo Roberto (orgs.). Federalismo e políticas educacionais na efetivação do direito à educação no Brasil. Brasília: IPEA, 2011.

FARENZENA, Nalú. A Política de financiamento da Educação Básica: rumos da Legislação Brasileira. Porto Alegre: Editora - UFRGS, 2006.

GOUVEIA, Andréa Barbosa; SCHNEIDER, Gabriela; SOUZA, Ângelo Ricardo de. Índice de Condições de Qualidade Educacional: metodologia e indícios. Estudos em Avaliação Educacional (Impresso), v. 11, p. 115-135, 2011.

PARO, Vitor Henrique. A gestão da educação ante as exigências de qualidade e produtividade da escola pública. In: SILVA, LUIZ HERON DA (Org.). A escola cidadã no contexto da globalização. Petrópolis: Vozes, 1998, p. 300-307.

PINTO, José Marcelino Rezende. A política recente de fundos para o financiamento da educação e seus efeitos no pacto federativo. Educação e Sociedade, v. 28, p. 877-897, 2007.

WALZER, Michael. Esferas da justiça: em defesa do pluralismo e da igualdade. Trad. Jussara Simões. São Paulo: Martins Fontes, 2003.

ZAMPIRI, Marilene. A disformidade no desenho da oferta educacional e a fragilização do direito à educação: um panorama da oferta de matrículas do ensino fundamental no Brasil. 2014. 155f. Tese (Doutorado em Educação) - 
Universidade Federal do Paraná, Curitiba, 2014.

ANDRÉA BARBOSA GOUVEIA é doutora em Educação pela Universidade de São Paulo e professora da Universidade Federal do Paraná (UFPR).E-mail: andreabg@ ufpr.br

ANDREA POLENA é mestranda do programa de pós graduação em educação na UFPR. E-mail: andrea.ufpr@yahoo.com.br

Recebido em outubro de 2014

Aprovado em dezembro de2014 